\title{
PROCEEDINGS OF THE PATHOLOGICAL SOCIETY OF GREAT BRITAIN AND IRELAND
}

The 136th meeting of the Society was held at the Preclinical Medical College, St Bartholomew's Hospital, London, on the 4th, 5th and 6th January 1978

\section{SYNOPSES OF PAPERS OF MICROBIOLOGICAL INTEREST}

These synopses should not be cited as references in published work without the permission of the authors.

\section{FaCtors influenCING in-VITRO ANTIBODY ENHANCEMENT By BCG}

Carolyn A. Brown, I. N. Brown and V. S. Sljivic

Departments of Immunology and Bacteriology, St Mary's Hospital Medical School, London W2 IPG

Mycobacteria are potent adjuvants in vivo but the way in which they act is still unclear. In order to eliminate some of the variables, we have concentrated on antibody production in an in-vitro system.

Heat-killed BCG added to suspensions of cultured murine-spleen cells causes an increased response in terms of antisheep-erythrocyte plaque-forming cells (PFC). The extent of this increase depends on the BCG concentration and whether or not the animals have been pretreated with BCG.

Spleen cells cultured with BCG produce a filterable PFC-enhancing factor. The enhancement again depends on the number of organisms present, and on the origin of the spleen cells.

\section{A STREPTOCOCCAL ANTIBODY OF THE IMMUNOGLOBULIN}

G CLASS THAT IS NOT ABSORBED BY STAPHYLOCOCCAL PROTEIN A

\author{
G. E. Mortimer and Jean P. Widdowson \\ Cross-Infection Reference Laboratory, Public Health Laboratory Service, \\ Colindale Avenue, London NW9 5 HT
}

Simple absorption tests based on the interaction of staphylococcal protein A with the Fc portion of immunoglobulin G (IgG) are widely used to distinguish between IgG and IgM antibodies in a variety of diseases. In investigations of the absorption of group-A streptococcal antibodies by protein-A-positive staphylococci, we found that the complement-fixing antibodies to a cellular antigen, $\mathrm{M}$-associated protein (MAP), were incompletely absorbed, in contrast to anti-streptolysin and anti-desoxyribonuclease B, which are completely absorbed. However, density gradient centrifugation showed that the MAP antibodies belonged to the IgG and not the IgM class. Evidence was obtained that the MAP antibodies are of restricted heterogeneity in that they belong disproportionately to the IgG3 subclass. IgG3 molecules do not interact with protein A. This study emphasises the need to confirm that antibodies apparently unreactive with protein A do in fact belong to the IgM class. 


\author{
18. EPidemiological eValuation of a PHAGe-tyPing \\ METHOD FOR GROUP-B STREPTOCOCCI \\ Jacqueline Stringer and W. R. Maxted \\ Cross-Infection Reference Laboratory, Public Health Laboratory Service, \\ Colindale Avenue, London NW9 5 HT
}

\begin{abstract}
The origin of the infecting group-B streptococcus in "late-onset" neonatal meningitis is uncertain. Little is known about the circumstances under which babies acquire the organism from non-maternal sources, and serological typing methods are insufficiently discriminating for the investigation of these. A recently developed phage-typing method for group-B streptococci was evaluated for discriminatory powers and reproducibility. Patterns of lysis by the typing phages were diverse, and permitted the recognition of numerous distinct strains within each serotype. Reproducibility was studied on collections of isolates each believed to be of common origin. It was concluded that a difference in typing pattern exceeding one strong reaction constituted reliable grounds for discrimination between strains. The method is thus suitable for prospective studies of the sources and routes of acquisition of group-B streptococci by newborn infants.
\end{abstract}

\title{
19. Detection of a gonococcal antibody by the elisa method
}

\author{
A. A. Glynn and Catherine Ison \\ Bacteriology Department, Wright-Fleming Institute, \\ St Mary's Hospital Medical School, London W2 IPG
}

\begin{abstract}
A satisfactory serological test for the presence of infection with Neisseria gonorrhoeae would be extremely useful both epidemiologically and in clinical diagnosis. Because the enzyme-linked immunosorbent assay (ELISA) offers a very sensitive technique for the detection of immunoglobulins of known class, we have adapted it to measure IgG antibodies to a protein antigen from gonococci. In a preliminary investigation of 400 male and female patients with gonorrhoea, significant antibody levels were found in $50 \%$ often within a few days of infection. Moreover, antibody was found in a similar proportion of symptomless carriers, male as well as female. Especially high levels occurred in patients with disseminated gonococcal infection and in men with rectal involvement. The false-positive rate appeared to be $8 \%$. Antibody levels did not appear to be affected by attacks of gonorrhoea occurring more than 3 months previously. Further evaluation is necessary but the antibody response may be of a rapid and short-lived type that would be ideal for diagnostic purposes. The pattern of IgM antibodies is different.
\end{abstract}

\section{The DEVELOPMENT AND ASSESSMENT OF A KLEBECINE TYPING SYSTEM}

\author{
A. S. Edmondson and E. M. Cooke \\ Department of Microbiology, School of Medicine, Leeds LS2 9NL
}

Although klebsiella infections have become of increasing importance, their study has been hampered by the absence of a generally-available typing system. Typing schemes based on the capsular swelling reaction or modifications of it require the preparation of large numbers of antisera.

In this paper we describe the setting up of a typing scheme based on klebecine sensitivity. The klebecine producer strains were chosen from a large number of strains by computer analysis of similarity values. By means of this method $97 \%$ of klebsiella strains isolated from hospital patients could be typed and not more than $9 \%$ of strains belonged to any one klebecine type. 
The application of the method to sporadic infections and to outbreaks of infection was described.

\title{
22. Cytomegalovirus ENDOLABYRINTHITIS
}

\author{
G. L. Davis
}

Department of Pathology, Institute of Laryngology and Otology, London WC1X 8EE

The role of human cytomegalovirus (CMV) in congenital deafness was studied. In an infant who died of cytomegalic inclusion disease soon after birth we observed that the virus infected labyrinthine epithelium, sparing neurosensory structures. Studies at the Royal National Throat, Nose and Ear Hospital showed that CMV-infected children have hearing defects. The similar histopathology of CMV endolabyrinthitis in four other necropsied cases indicated that CMV spreads to the inner ear via the stria vascularis.

Experimental murine-CMV perilabyrinthitis involved connective tissues and the acoustic nerve. The absence of CMV replication in endolabyrinthine epithelium was confirmed by incubation of foetal mouse otocysts with murine CMV. The model more closely resembled human perilabyrinthitis caused by the viruses of herpes simplex, varicella and zoster than that caused by CMV. Immunopathological studies suggested that, though related viruses may have common patterns of cellular infection, the ability of viruses to replicate is determined by host factors.

\section{SYMPOSIUM: THE ROLE OF THE MACROPHAGE IN DISEASES}

\section{THE ROLE OF MACROPHAGES IN DISEASE}

\author{
W. G. Spector \\ Histopathology Department, St Bartholomew's Hospital, London EC1
}

The macrophage plays a central role in chronic inflammation. Research over the past few years has illuminated this role and has stressed the importance of activation and secretion. There is also new information about the formation from macrophages of epithelioid cells and giant cells. The role of mononuclear phagocytes in the host reaction to neoplasia is still contentious but there is growing evidence that some lymphomas originate in neoplasia of this cell line.

\section{MaCrophage activation}

\author{
A. C. Allison \\ Clinical Research Centre, Watford Road, Harrow, Middlesex HA1 3UJ
}

Cells of the mononuclear phagocyte lineage can be activated by products of activated' $\mathrm{T}$ lymphocytes, immune complexes or the complement-cleavage product $\mathrm{C} 3 \mathrm{~b}$. These three: mechanisms account for macrophage activation in vivo. When activated, the cells show increased protein synthesis, secretion of hydrolytic enzymes and activated complement. components, increased levels of tissue thromboplastin, and release of endogenous pyrogen and colony-stimulating factor, as well as increased capacity to kill bacteria, tumour cells and intracellular parasites. The role of these effects in the pathogenesis of chronic inflammation and in immunity against communicable diseases was discussed, together with several mechanisms by which macrophages kill tumour cells or limit their multiplication. 


\title{
35. THE ROLE OF THE MACROPHAGE IN THE IMMUNE RESPONSE
}

\author{
M. Baltz \\ Department of Zoology, University College, London
}

Macrophages play an important role in both the initiation and the regulation of immune responses in vivo and in vitro. It has been demonstrated by a variety of approaches that macrophages participate in the activation of thymus-derived $(\mathrm{T})$ and bone marrow-derived (B) lymphocytes. However, the mechanism by which macrophages participate in activation and in T and B lymphocyte collaboration is as yet unresolved and controversial. Possible mechanisms might embrace the role of the macrophage as an antigen-focusing cell and the role of both antigen-specific and non-specific soluble factors secreted by macrophages.

Although immune specificity has traditionally been considered to be a lymphocyte function, there is increasing evidence to suggest that macrophages can exhibit some degree of immune specificity. Such specificity would appear to be specificity of "determinant selection ", i.e., antigen must be presented to $\mathrm{T}$ lymphocytes in the proper conformation for antigen recognition and subsequent activation. A current proposal is that products of the major histocompatibility complex (MHC), specifically-immune-response region (Ir) gene products, may be expressed at the level of the macrophage and may play a role in determinant selection.

Mechanisms and theories of T and B lymphocyte activation by macrophages and the role of Ir gene products were discussed.

\section{SYMPOSIUM: ANAEROBIC BACTERIOLOGY: EVOLVING CONCEPTS AND PRACTICE IN RELATION TO HEALTH AND DISEASE IN MAN}

\section{ANAEROBIC METHODOLOGY}

\author{
J. G. Collee \\ Department of Bacteriology, University Medical School, Edinburgh EH8 $9 A G$
}

The laboratory growth of an exacting anaerobe requires that an adequate inoculum of viable cells is brought to a suitably nutritious medium which is maintained in an adequately reduced state at an appropriate temperature; in practice, these requirements demand attention to detail in sampling, transit and laboratory processing. Oxygen-free gassing systems and anaerobic cabinets have contributed to research and development, but the quantitative growth of the presently-recognised anaerobic pathogens of man can be achieved with a good anaerobic jar.

Developments in anaerobic jar design must be periodically assessed. The amount of catalyst and the recommended gas mixture, including the use of gas-producing packs, merit consideration. The swab is an inefficient sampling device. The relative advantages of freshly poured media, pre-reduced media and anaerobically stored media must be related to routine laboratory practice and practicability.

Laboratories concerned with the routine investigation of anaerobic bacteria of man can be encouraged to use anaerobic jars and a conventional procedure at the bench, provided that (i) the jars are properly designed, engineered and serviced, (ii) the anaerobic procedure is defined, (iii) a proper amount of catalyst is used under safe conditions with a correct gas mixture and (iv) the culture media and techniques are suitably selected. 


\title{
38. THE IDENTIFICATION OF THE PATHOGENIC CLOSTRIDIA
}

\author{
P. D. Walker \\ Wellcome Research Laboratories, Langley Court, Beckenham, Kent
}

Methods used for the identification of pathogenic clostridia are, with few exceptions, traditional. Isolation of clostridia can be achieved fairly easily on laboratory media by means of conventional techniques that include the use of the anaerobic jar in its various forms. Many species have a characteristic colonial morphology which, together with Gram-stained smears of sporulating bacilli, are of considerable assistance in preliminary identification. In addition, the incorporation of various indicators such as blood and lecithin into the growth medium is of value. Examination of filtrates for exotoxins either in mice or in guinea-pig skins completes the process of identification.

The fluorescent staining technique has been extremely useful in identifying species of clostridia that are important in veterinary medicine and has the advantage that it obviates the need to isolate the organism. In this way a quick and simple identification can be achieved.

Other techniques such as gas chromatography may be of assistance.

\section{The ANAERobic COCCI: CAN WE BE MORE DEFINITE?}

\author{
Brian Watt \\ Central Microbiological Laboratories, Western General Hospital, \\ Edinburgh EH4 $2 \mathrm{XU}$
}

The obligately anaerobic cocci can be associated with serious and important infections in man, yet they remain a neglected group of organisms. One reason for this neglect may be the confused state of their classification; different workers have proposed different classification schemes and some have allowed inclusion of micro-aerophilic strains. The complexity and diversity of these schemes have prevented many diagnostic laboratories from undertaking any characterisation of the organisms, which are usually lumped together as " anaerobic streptococci ". A study of a large number of clinical isolates and reference strains has not only furnished information on methods for the growth and recovery of these organisms, but has also provided evidence to support a clear definition of " anaerobic cocci" that distinguishes obligately anaerobic from micro-aerophilic strains. The uses and limitations of sensitivity testing to metronidazole in this context were discussed.

A clear definition of anaerobic cocci allows a more definite approach to the characterisation of strains in the diagnostic laboratory as well as to the study of their role in human health and disease.

\section{THE CHARACTERISATION OF GRAM-NEGATIVE ANAEROBIC BACILLI}

\section{B. I. Duerden \\ Department of Medical Microbiology, University of Sheffield Medical School, Sheffield}

Both the classification of the Bacteroidaceae and our understanding of the relationship between the various species are undergoing considerable changes. Gram-negative anaerobic bacilli can be divided into four groups: the "fragilis" group, the "melaninogenicusoralis" group, the "asaccharolytic" group and the "fusobacteria". The fragilis group contains the species previously designated as subspecies of Bacteroides fragilis and several related species; all are commensals of the large intestine. They are saccharolytic nonpigmented organisms that produce succinate as a major end-product of metabolism; the group is generally tolerant of bile or taurocholate and resistant to disks containing penicillin 
(1.5 units), neomycin $(1000 \mu \mathrm{g})$ and kanamycin $(1000 \mu \mathrm{g})$. The melaninogenicus-oralis group contains the fermentative subspecies of $B$. melaninogenicus and non-pigmented species that share similar characteristics (B. oralis, $B$. ruminicola etc.); they are inhibited by bile or taurocholate and are sensitive to penicillin and neomycin disks. Pigment production is no longer the sole basis for the identification of $B$. melaninogenicus. The asaccharolytic group includes $B$. asaccharolyticus (formerly $B$. melaninogenicus ss asaccharolyticus), $B$. corrodens and other non-pigmented non-fermentative species. The fusobacteria are generally non- or weakly-fermentative strains that produce major amounts of $n$-butyric acid. This classification is based upon the results of complex biochemical investigations. However, most isolates may be identified by routine bacteriological methods.

\section{The BIOChemical Potential of ANAERoBes in THE GUT}

\section{J. Hill \\ Central Public Health Laboratory, Colindale Avenue, London NW9 $5 H T$}

Because the anaerobic bacteria outnumber aerobes by a factor of 100 to 1000 , the biochemical activity of the gut anaerobes is identical to the activity of the total gut flora.

Bacterial glycosidases are important in the metabolism of plant glycosides, many of which yield pharmacologically-active aglycones, such as the cathartics senna and cascara, and the cardioactive lanatosides. Some aglycones are lethal, such as those from amygdalin and cycasin.

The gut bacteria produce a range of amines and secondary amines from amino acids; these secondary amines can be further metabolised to $\mathrm{N}$-nitrosamines, potent carcinogens that have been implicated in the causation of gastric cancer. The products of bile acid degradation have been implicated in the causation of bowel cancer.

\section{Clinical consequences of bacterial overgrowth in the SMALL INTESTINE}

\section{Soad Tabaqchali \\ Department of Medical Microbiology, St Bartholomew's Hospital, London}

There are numerous conditions that lead to stasis and to bacterial proliferation within the small intestine. The bacterial flora colonising the small intestine in these conditions is different from the normal flora. It is qualitatively similar to the faecal flora and may be present in high concentrations in intestinal fluid $\left(10^{5}-10^{9}\right.$ organisms per $\left.\mathrm{ml}\right)$. The bacteria are metabolically active and can interfere with normal intestinal function and lead to malabsorption and nutritional deficiencies in the host. The type of malabsorption depends on the site and extent of the causative lesion. Bacterial deconjugation and dehydroxylation of bile salts contribute to steatorrhoea, diarrhoea and interference with the absorption of fat-soluble vitamins. Other mechanisms for bacterial interference with vitamin $\mathbf{B}_{12}$ absorption and protein metabolism leading to nutritional deficiencies were discussed.

\section{Pre-operative Control of anaerobic bacteria in RELATION TO THE PREVENTION OF POST-OPERATIVE SEPSIS}

\section{A. T. Willis}

\section{Public Health Laboratory, Luton and Dunstable Hospital, Luton LU4 ODZ}

Anaerobic infections in man are common and are usually caused by non-clostridial anaerobes. These infections are almost always endogenous as the non-sporing anaerobes obligate parasites of the oropharynx and of the alimentary and female-genital tracts, from whence they may invade adjacent tissues that are debilitated or are the seat of some other 
pathological change. The trauma of abdominal surgery, expecially bowel and gynaecological procedures, provides conditions favourable to the development of " bacteroides " infections.

The average frequency of post-operative infections following appendicectomy is around $30 \%$, and infection remains the principal complication of colonic surgery and is also an important cause of morbidity following hysterectomy. Most of this post-surgical sepsis is due to anaerobes. Over the years, efforts to reduce the incidence of this sepsis have led surgeons to employ a great variety of topical and systemic prophylactic-antibacterial regimens, many of which have had only limited success because they utilise drugs that are inactive or erratically active against anaerobic organisms.

The prophylactic use of metronidazole in gastrointestinal and female-genital tract surgery has been conspicuously successful in the prevention of post-operative sepsis. In appendicectomy and hysterectomy patients on the one hand, and in patients subjected to major colonic surgery on the other, its prophylactic use may confidently be expected to reduce anaerobic sepsis rates of around $20 \%$ and $50 \%$ respectively, to nil.

\section{TRENDS IN THE ANTIMICROBIAL THERAPY AND MANAGEMENT OF ANAEROBIC INFECTIONS}

\section{J. B. Selkon and H. R. Ingham}

Public Health Laboratory, General Hospital, Newcastle upon Tyne

The increased awareness of the importance of obligate anaerobes, in particular Bacteroides fragilis and $B$. melaninogenicus, in serious infections such as cerebral abscess and abdominal sepsis has led to the routine inclusion of agents active against the organisms in the chemotherapeutic regimens used in these conditions. The use of chloramphenicol was followed by lincomycin and then clindamycin when these drugs became available. Currently the nitroimidazole, metronidazole, is the drug of first choice because of its rapid bactericidal activity and relative freedom from unwanted side effects. The cephamycins have now to be considered as a further alternative in intra-abdominal sepsis.

The recent evidence of the ability of certain anaerobes to interfere in vitro with phagocytosis and killing of aerobic bacteria has demonstrated a mechanism for the synergistic activity of anaerobes in mixed infections. This role of the anaerobes emphasises the necessity for highly bactericidal chemotherapy to be directed against them in treating these infections.

\section{THE FAECAL FLORA OF BREAST-FED INFANTS AND CHILDREN IN LONDON AND NIGERIA}

\section{B. S. Drasar*, Sarah C. Oswald*, Phylis Rogers $†$ and A. M. Tomkins $\ddagger$ \\ * Department of Medical Microbiology and $\dagger$ Department of Human Nutrition, London School of Hygiene and Tropical Medicine, and $\ddagger$ Clinical Nutrition and Metabolism Unit, Hospital for Tropical Diseases, London NWI}

Differences in the faecal flora have been observed when groups of people of very different dietary habit, environmental circumstance and ethnic origin have been compared. These differences have been explained in terms of diet. Attempts to alter the flora by changing the diet have proved disappointing. In contrast, studies of infant feeding practice have shown the importance of diet in determining the composition of the faecal flora in babies.

The bacterial flora of faeces obtained from babies and weaned pre-school children in London and in Malumfashi, Nigeria have been examined. Breast-fed babies from both places had a similar flora, dominated by bifidobacteria, despite differences in the environment. Bacteroides organisms were more common in weaned children from London than in those from Nigeria, even though both groups were initially wholly breast-fed.

It seems probable that infant feeding and weaning practice may determine the flora in adults. 


\title{
46. THE INTESTINAL-MUCOSAL FLORA IN CROHN'S DISEASE
}

\author{
Susan Peach, R. Lock, D. Katz and Soad Tabaqchali \\ Department of Medical Microbiology, St Bartholomew's Hospital, London EC1
}

Previous bacteriological studies of Crohn's disease have concentrated on the intestinal lumen and little is known of the bacterial flora associated with the mucosa of the intestine. We examined the bacterial flora of the mucosa of patients with Crohn's disease and compared it with the mucosal flora of a control group. Specimens were obtained at operation from patients undergoing intestinal surgery. Whole-thickness intestinal sections were taken from the diseased segment and from a portion of uninvolved intestine. Each specimen was examined histologically. Twenty-two specimens of Crohn's tissue (12 ileum, 10 colon) and 16 control specimens from small and large bowel were examined by strictly anaerobic techniques in an anaerobic chamber.

A mucosal flora was found to exist in all the large bowel samples and in three-quarters of the small bowel samples. It was qualitatively similar in all the samples, consisting mainly of Gram-positive facultative anaerobes. Greater numbers of bacteria were associated with colonic tissue (106-107 per gram) than with tissue from the jejunum $\left(10^{3}-10^{4}\right.$ per gram). This difference was statistically significant $(P<0.03)$. Samples from the terminal ileum were quantitatively intermediate between those from the jejunum and colon.

There was no statistical difference between Crohn's disease tissue and histologically normal tissue from the control group in respect of the numbers of tissue-associated bacteria.

\section{THE IDENTIFICATION OF STRAINS OF BACTEROIDES SPP. FROM NORMAL HUMAN FAECES AND FROM CLINICAL INFECTIONS}

\author{
B. I. Duerden \\ Department of Medical Microbiology, \\ University of Sheffield Medical School, Sheffield
}

Strains (342) of Bacteroides spp. were identified by a short combined set of biochemical, antibiotic-disk resistance and tolerance tests; 197 were faecal isolates from 20 normal human subjects and 145 were isolated from 129 routine clinical specimens, sent to the diagnostic laboratory. The results of these tests enabled the isolates to be allocated to one of four groups-" fragilis ", " melaninogenicus-oralis", " asaccharolytic" and "fusobacteria "and most isolates were identified as belonging to recognised species within these groups. One hundred and seventy-four faecal isolates were allocated to the fragilis group and were divided between several species within that group; only 20 strains were $B$. fragilis ( $B$. fragilis $\mathrm{ss}$ fragilis). However, 75 out of 89 clinical isolates allocated to the fragilis group were $B$. fragilis; 66 out of 92 clinical isolates from infections related to the appendix or large intestine were allocated to the fragilis group and 54 of these were $B$. fragilis. The remaining faecal isolates were $B$. melaninogenicus (3), pigmented $B$. asaccharolyticus (8) and non-pigmented asaccharolytic strains (12). The other clinical isolates were identified as melaninogenicusoralis group (17), pigmented B. asaccharolyticus (30), B. corrodens (3), non-pigmented asaccharolytic strains (3) and fusobacteria (3).

\section{SEROLOGY OF BACTEROIDES FRAGILIS}

\section{K. M. Elhag and Soad Tabaqchali Department of Medical Microbiology, St Bartholomew's Hospital, London ECI}

Bacteroides fragilis is the anaerobic micro-organism most commonly associated with clinical infections. For this reason several attempts at classification based on its antigenic 
properties have been investigated. We have recently developed a simple serological scheme for the classification of $B$. fragilis based on the agglutination test. Twenty type-specific antisera and 20 distinct serogroups (nos. 1-20) of B. fragilis were obtained. By means of the 20 absorbed antisera, we screened 322 strains of $B$. fragilis isolated from clinical specimens from three different hospitals.

Of the isolates, $41 \%$ agglutinated with only one of the antisera and could be allocated to one or other of the various serogroups. A further $21 \%$ agglutinated with more than one antiserum, and the remainder showed no reactions. The majority of the typable isolates belonged to serogroups 2,17 and 19 which consisted of $B$. fragilis ss fragilis. None belonged to serogroups 4, 9, 14 and 15 which consisted of other subspecies of $B$. fragilis.

Similar distributions of serogroups were found in the three hospitals, but certain serogroups predominated in each hospital. No relationship was found between the site of infection and the serogroup of the infecting organism. The distribution of serogroups among the different clinical isolates and their relationship to biotypes were discussed.

This simple classification scheme may prove to be useful in diagnostic and epidemiological investigations.

\author{
49. The APPLICATION OF HEAD-SPACE ANALYSIS GAS-LIQUid \\ CHROMATOGRAPHY TO THE DIAGNOSIS OF ANAEROBE INFECTION
}

\title{
A. J. Taylor \\ Central Public Health Laboratory, Colindale Avenue, London NW9 $5 H T$
}

Gas-liquid chromatographic (GLC) analysis has become an established method of diagnosis of infection by anaerobic bacteria by detecting volatile fatty acids produced in pus. Previously reported techniques have relied either on solvent extraction of metabolites from the clinical specimen or on injection of the specimen directly into the chromatograph; this reduces the column life or necessitates a modified column system. Head-space analysis allows a rapid answer to be obtained without extraction or modification of the chromatograph. Results of analysis of 50 specimens of pus from sites likely to yield anaerobic bacteria show a correlation of more than $90 \%$ between detection of volatile fatty acid and subsequent recovery by culture of anaerobes in significant numbers.

A reliable transport system suitable both for culture of anaerobes and direct GLC analysis. was also described.

\section{GAS-liquid CHROMATOGRAPHIC (GLC) ANALYSIS OF METABOLIC PRODUCTS IN THE IDENTIFICATION OF BACTEROIDACEAE OF CLINICAL INTEREST}

\author{
A. G. Deacon \\ Department of Bacteriology, The Medical School, \\ Ninewells Hospital, Dundee DD2 1UB
}

The acid end-products in broth cultures of 185 isolates of the family Bacteroidaceae were separated and analysed by gas-liquid chromatography. Different media were evaluated; definitive studies were performed in a fully-supplemented complex medium. The limitations of this approach to the identification of a wide range of strains from various clinical sources were determined and the results were correlated with those of a series of morphological, biochemical, tolerance and antibiotic-resistance tests.

All test strains were identified to generic level on the basis of simple microscopical and colonial observations and GLC analysis; additional tests were required to allow species or subspecies identification of most strains. Population differences were detected between some species or subspecies by quantitative analyses of fatty acids, but individual strains could not 
always be separated because of overlapping ranges of distribution of acids that were common products of more than one species or subspecies. Small differences in minor products between different species or subspecies were variable and were not considered adequate for discrimination without support from other observations.

The potential application of the GLC technique to the rapid and accurate identification of the Bacteroidaceae in hospital laboratories were discussed.

\title{
51. DifFerent BeHAVIOUR PATTERNS OF E. COLI IN THE MOUSE KIDNEY
}

\author{
J. F. van den Bosch*, J. de Graaff† and D. M. MacLaren*
}

Departments of * Medical Microbiology and $\dagger$ Oral Microbiology, The Free University, P.O. Box 7161, Amsterdam, The Netherlands

Different $E$. coli strains, mostly isolated from cystitis, were injected intravenously into mice, and their behaviour in the mouse kidney was studied by determining the viable count in the kidneys of animals randomly chosen and killed at intervals up to $8 \mathrm{~h}$.

In relation to a reference point of $0.1 \%$ of the inoculum at time zero, the strains fell into four groups characterised by the following behaviour patterns. (1) The viable count in the kidneys fell and remained low for $8 \mathrm{~h}$. (2) the viable count first fell, then rose after $4 \mathrm{~h}$ to at least the level of the reference point. (3) The viable count rose rapidly and remained high; in this group early deaths were often seen. (4) The viable count stayed at approximately the level of the reference point for $8 \mathrm{~h}$.

The same four behaviour patterns were found in both Dutch and English strains. A correlation was found between the behaviour pattern and the LD50. There was no relationship between the behaviour pattern and the $\mathrm{O}$ serotype or the presence of $\mathrm{K}$ antigen.

\section{THE EFFECT OF RELEASED TISSUE PROTEASES IN DETERMINING THE OUTCOME OF MENINGOCOCCAL DISEASE}

J. M. Stark, B. M. Greenwood*, S. Lewis*, N. Matthews, H. C. Ryley and H. C. Whittle*

\author{
Department of Medical Microbiology, Welsh National School of Medicine, Cardiff \\ and ${ }^{*}$ Departments of Medicine and Paediatrics, Ahmadu Bello University, Zaria, Nigeria
}

The rate of release of tissue proteases by endotoxin is important in determining the outcome of meningoccal infection; if the rate is so great as to overwhelm the proteolyticinhibitor response, the interlinked control of many proteolytic cascades is upset, with disastrous clinical effects.

This conclusion is based on the examination of sera from Nigerian patients suffering from meningococcal infection of widely different degrees of severity. The concentrations of the major inhibitors of proteolysis ( $\alpha_{2}$ macroglobulin, $\alpha_{1}$ antitrypsin, $\alpha_{1}$ antichymotrypsin, inter- $\alpha$-trypsin inhibitor), of thrombosis (antithrombin III) and of the complement system (C1-esterase inhibitor, C3b inactivator) were estimated. These were correlated with the clinical state as well as C3 and $\alpha_{1}$ acid-glycoprotein concentrations, and were compared with the values from age-matched control samples.

The interpretation does not discount the value of antibody-which would reduce the effective amount of endotoxin inducing enzyme release-but allows that susceptibility in a particular individual could be affected by the quantity of proteolytic enzyme within lysosomes, lysosomal lability and the ability to produce effective inhibitors quickly. 


\title{
53. THE INHIBITION OF NEISSERIA GONORRHOEAE BY NORMAL HUMAN SALIVA
}

\author{
A. Mellersh, A. Clark and S. Hafiz \\ Department of Medical Microbiology, University of Sheffield Medical School, Sheffield
}

Despite the increased incidence of pharyngeal gonorrhoeae, no studies appear to have been undertaken on the effect of saliva on Neisseria gonorrhoeae. In this investigation we found that human saliva strongly inhibited the growth of $N$. gonorrhoeae on solid media and in liquid media. In contrast, saliva had little or no effect upon a wide range of bacteria that included $N$. meningitidis and commensal neisseriae. This specific action of saliva appeared to be bacteriostatic and the activity was destroyed by heating at $75^{\circ} \mathrm{C}$ for $5 \mathrm{~min}$. but was not affected by ultra-violet light. The active fraction was not dialysable and was precipitated with $35 \%$ saturated ammonium sulphate. By gel chromatography of saliva on Sephadex G75, it was possible to separate a fraction that appeared to be responsible for the inhibition of growth of $N$. gonorrhoeae.

One of the most interesting aspects of this observation is the peculiar specificity of the effect for the gonococcus, which seems to indicate some major difference between cell wall structure in this organism and that in all other members of the genus.

\section{TERMINATION OF AN OUTBREAK OF INFECTION DUE TO A GENTAMICIN- AND AMIKACIN-RESISTANT STAPHYLOCOCCUS AUREUS BY PROHIBITING THE USE OF GENTAMICIN}

\author{
M. Reynolds, K. Watters, F. R. Falkiner, P. Gargan, M. Lynch and C. Kane \\ Microbiology Laboratory, Adelaide Hospital, Dublin 8
}

Outbreaks of infection with gentamicin-resistant Staphylococcus aureus have been widely reported from the British Isles. The isolates have invariably been sensitive to amikacin. We report an outbreak of infection due to a strain of $S$. aureus that was resistant to numerous antimicrobial drugs including gentamicin and amikacin. Seven patients, widely distributed in the hospital, were involved over a 7-week period. Cultures from sputum and wounds yielded the same strain (phage type 85); it was resistant to gentamicin and amikacin (MIC > $32 \mathrm{mg}$ per litre). In most instances the micro-organism did not appear to play a pathogenic role. During epidemiological investigations the epidemic strain was isolated from the nose, throat, hair and perineum of patients and staff. Nasal carriers were treated with Naseptin and skin carriers with hexachlorophane baths. This ended the carrier state in all but one instance. Initially an attempt was made to limit the spread of infection by "barrier-nursing" and where possible infected patients were discharged. No adequate isolation facilities were available. These measures proved ineffective, but shortly after the use of systemic gentamicin was prohibited, the outbreak ceased. Topical gentamicin and amikacin are not used in this hospital.

\author{
55. ACQuisition of ANTIBIOTIC RESISTANCE BY \\ STAPHYLOCOCCUS AUREUS IN SKIN PATIENTS \\ Jay Naidoo and W. C. Noble \\ Department of Bacteriology, Institute of Dermatology, London E9 $6 B X$
}

Patients with diseases of the skin are frequently treated with topical antibiotics. As a result the staphylococci that colonise or infect their skins acquire resistance to these topical antibiotics. We have recently studied the apparent acquisition of resistance to gentamicin, neomycin, fucidin and lincomycin. One strain of Staphylococcus aureus initially resistant to 
penicillin, tetracycline, erythromycin and methicillin became resistant in addition to gentamicin, fucidin and lincomycin during a course of therapy in two patients. This strain was responsible for clinical infection in six of nine patients colonised. In another strain of $S$. aureus, initially resistant to penicillin, resistance to gentamicin and neomycin has appeared during therapy. The stimulus for the occurrence of gentamicin and neomycin resistance has been the topical application of the antibiotics. Plasmids govern resistance to gentamicin and neomycin. Lincomycin resistance occurred after oral dosage with erythromycin followed by dalacin. Fucidin resistance appeared before fucidin was used therapeutically. Lincomycin resistance occurred in a strain with dissociated resistance to erythromycin.

The appearance of resistance and the nature of the genes mediating resistance were discussed with reference to specific case histories.

\section{TRANSMISSION OF PLASMIDS GOVERNING GENTAMICIN RESISTANCE IN STAPHYLOCOCCUS AUREUS ON HUMAN AND ANIMAL SKIN}

\section{W. C. Noble and Jay Naidoo \\ Department of Bacteriology, Institute of Dermatology, London E9 $6 B X$}

During studies of the acquisition of resistance to antibiotics by strains of Staphylococcus aureus, we observed that two strains, carried by one patient, became resistant to gentamicin during therapy. One strain that was initially resistant to penicillin, tetracycline, neomycin and erythromycin could not be shown to carry phage, but had the phage-typing pattern $77 / 84 / 90$. The other strain, initially resistant to penicillin, tetracycline, erythromycin and methicillin, was lysogenic but non-typable (NT). When the 77/84/90 strain and the gentamicin-resistant variant of the NT strain were mixed in culture in vitro, a few " recombinants " occurred that were resistant to gentamicin and neomycin but sensitive to methicillin and had the pattern 77/84/90. This was presumably the result of phage transduction. With these strains transduction occurs with much greater frequency on human skin and to a lesser extent on the skins of the obese-hairless mice bred in our Institute.

\section{RETICULO-ENDOTHELIAL BLOCKADE: A RE-ASSESSMENT}

\section{J. W. B. Bradfield \\ Department of Pathology, University of Bristol}

The features of reticulo-endothelial (RE) blockade have traditionally been characterised by studying the kinetics of clearance of test particles from blood. This report describes what happened when some of these features were re-examined by measuring the distribution of test particles in various organs. Blockade was induced in mice by means of intravenous dextran sulphate and assessed by measuring the distribution in various organs of ${ }^{51} \mathrm{Cr}$ labelled sheep red-blood cells (SRBC) injected intravenously. After RE blockade there was a decrease in the total uptake of SRBC by the liver, but the total uptake in the spleen and bone marrow was increased. For this reason "RE blockade" would seem an inappropriate term: Kupffer-cell blockade would be more accurate. With progressive Kupffer-cell blockade, there was progressive lengthening of the clearance time of SRBC from the blood, showing that the rates of transfer from blood to spleen and bone marrow were insufficient to compensate for decrease in the rate of hepatic uptake. The organ-uptake data showed that, whereas a single exponential curve might be appropriate to describe transfer from blood to liver in normal animals, it is not appropriate in blockaded animals in which most of the SRBC are cleared by the spleen and bone marrow. The measurement of RE blockade was not dependent on the dose of SRBC used; this contrasts with many previous blood-clearance studies with other test agents that had to be injected in doses large enough almost to saturate the Kupffer cells. 
In short, some of the features that have been attributed to RE blockade and its measurement may be artifacts produced by earlier experimental methods. By following the altered fate of intravenous particles excluded from the liver by Kupffer-cell blockade, new biological implications of the phenomenon have been demonstrated.

\author{
62. USE OF LYSOSTAPHIN TO REMOVE CELL-ADHERENT \\ STAPHYLOCOCCI DURING IN-VITRO ASSAYS OF PHAGOCYTE FUNCTION \\ C. S. F. Easmon, P. Cole* and Heather Lanyon* \\ Bacteriology Department, Wright-Fleming Institute, St Mary's Hospital Medical \\ School, London W2 IPG and * Host Defence Unit, Cardiothoracic Institute, Fulham \\ Road, London SW3 6HP
}

One of the main problems with in-vitro tests of phagocyte function is the removal of cell-adherent bacteria. Antibiotics are not wholly satisfactory for this purpose as they kill bacteria too slowly and can, in some instances, enter phagocytic cells. Lysostaphin is a bacteriolytic enzyme that rapidly kills staphylococci but does not enter human polymorphs. We have used lysostaphin to remove cell-adherent Staphylococcus aureus during in-vitro assays with human blood phagocytes. The staphylococci were labelled with ${ }^{3} \mathrm{H}$ thymidine and intracellular and total counts were measured with a liquid scintillation counter. After incubation for $15 \mathrm{~min} .86 \%$ of the total count was cell-associated but treatment of the cells with lysostaphin reduced this to $54 \%$.

We have used lysostaphin to remove $S$. aureus from glass-adherent human-alveolar macrophages. These cells, unlike polymorphs, took up lysostaphin when exposed to high concentrations of the enzyme for several hours, but such conditions were not necessary for the killing of $S$. aureus.

\title{
SYMPOSIUM: VIRUS INFECTIONS IN PATIENTS AT A DISADVANTAGE IMMUNOLOGICALLY
}

\author{
70. Virological COMPLiCATIONS OF RENAL ALLOGRAFT \\ TRANSPLANTATION \\ J. C. Coleman \\ Department of Medical Microbiology, \\ Charing Cross Hospital Medical School, London W6
}

Many renal-allograft recipients develop infections by members of the herpes group of viruses. Of these, cytomegalovirus infections are the most common, although herpes simplex and varicella-zoster virus infections are also seen. Cytomegalovirus infections appear usually to be due to activation of latent infection, although some cases are undoubtedly associated with the transplantation of a kidney from a seropositive donor into a seronegative recipient.

During immunosuppressive treatment the complement-fixing antibody titres are depressed below their pre-transplantation levels. The development of active disease may be signalled by a rise in antibody titre that is often accompanied by virus excretion in the urine. The clinical manifestations include pyrexia, leucopenia, arthralgia, pneumonia, hepatitis and encephalitis. Active cytomegalovirus infections are also associated with the clinical signs of graft rejection. Double infections involving cytomegalovirus and another virus, either 
herpes simplex or varicella-zoster, have been described. Evidence of dual infection with herpes group viruses is associated with a very poor prognosis.

Infections by other viruses, e.g., influenza or mumps virus, do not appear clinically to be more serious than in normal patients. There does not appear to be an association between the presence of hepatitis-B surface antigen or antibody and graft rejection.

\title{
71. VIRUS INFECTIONS IN BONE MARROW RECIPIENTS
}

\author{
Gudrun Agnarsdottir \\ Royal Postgraduate Medical School, Hammersmith Hospital, Du Cane Road, \\ London W12 OHS
}

Recipients of bone marrow transplants form a special group among immunosuppressed patients. Immunosuppression is often a feature of their primary disease and their immune system is further suppressed by intensive treatment to enable them to retain their graft. This makes them particularly susceptible to infection with opportunistic pathogens, which often lead to death. Many of these infection are due to reactivation of latent viruses harboured by the patient from an episode of primary infection earlier in life, while others are due to infection acquired during the period of immunosuppression.

The viruses that most frequently produce disease in bone marrow recipients belong to the herpesvirus group. Of these, cytomegaloviruses in particular are often involved and are responsible for more episodes of illness in transplant patients than is either herpes simplex, varicella-zoster or Epstein-Barr virus. There is some evidence from clinical experience as well as from work in animals that reactivation of cytomegalovirus is closely associated with the process of graft rejection. The diagnosis and prevention of this infection was discussed.

\section{Papovaviruses in PREgNANCY}

\author{
D. V. Coleman, R. A. Daniel, W. J. I. Russell, S. D. Gardner*, \\ A. M. Field* and P. E. Gibson* \\ Department of Experimental Pathology, St Mary's Hospital Medical School, \\ London W2 $1 N Y$, and \\ * Virus Reference Laboratory, Public Health Laboratory Service, Colindale Avenue, \\ London NW9 $5 H T$
}

We report the preliminary results of a prospective study of pregnant women for evidence of active infection with the human papovaviruses BK and JC. This study has been in progress for one year and, so far, over $\mathbf{8 0 0}$ women have been enlisted into the project. Urine and serum samples were collected throughout pregnancy together with details of the clinical progress of the pregnancies. Cord blood was obtained at delivery and details concerning neonatal development, e.g., birth weight and head circumference, were recorded.

Stained smears of urinary sediment were screened routinely by light microscopy for cytological evidence of virus infection. The presence of inclusions in the nuclei of urothelial cells was considered an indication for further examination of urine by virus isolation techniques and electronmicroscopy.

Virus infection was suspected from cytological findings in 20 of 319 patients $(6.27 \%)$ who have subsequently delivered. Active infection with papovavirus has been confirmed in seven of the 20 cases by virus isolation, or electronmicroscopy, or both. A papovavirus has been isolated from five of the seven cases and one isolate has been positively identified as JC strain. Serological studies indicate that the seven patients include three others with JC-strain infection. 


\section{THE EFFECT OF IMMUNOSUPPRESSION ON EXPERIMENTAL} RESPIRATORY-VIRAL INFECTION

R. B. Heath

St Bartholomew's Hospital, London ECI

Infection of mice with either the Sendai strain of parainfluenza virus or the Kunz strain of influenza virus provides a suitable model of viral disease of the upper respiratory tract of man, as both viruses are non-lethal and are confined to the airways. Immunosuppression, achieved by the administration of cytophosphamide converts these relatively harmless infections into fatal pneumonic diseases. The pathogenesis of these altered infections were described.

Cell-mediated immunity (CMI) develops during the course of the infections. The effect of selective suppression of CMI by means of thymectomy, irradiation and bone marrow reconstitution were described.

The relevance of these findings to chest infection in immunologically compromised patients were discussed. 